\section{EMERGING PATTERNS IN THE RESISTANCE TO THE MEDICALIZATION OF BIRTH IN NORTH AMERICA}

Childbirth is one of the most ubiquitous experiences of human life. It is an integral ritual of the life cycle. Nevertheless, different cultures have evolved strikingly varied practices surrounding childbirth. As such, one might argue that in any society, "the way a woman gives birth and the kind of care given to her point as sharply as an arrowhead to the key values in the culture (1)."

Within the last century, the process of childbirth has increasingly taken place within the realm of medicine: in a hospital, attended by a physician. This medicalization of childbirth is especially evident in Western societies with an established technomedical infrastructure such as in "non-Indigenous" North America and societies where the medicalization of birth has been imposed such as in Inuit communities. This paper will explore women's concerns regarding the medicalization of childbirth, as illustrated by the example of the Inuit women in Canada.

In North America, the ritual of birth was once the dominion of women, but has since been incorporated into the practice of medicine, causing a shift of "authoritative knowledge" from older women and midwives to trained physicians. The increasing reliance of medicine on technology within North American society has permeated the realm of childbirth. In so doing, the framework of empirical science has been introduced into the birthing process, perpetuating the values of a technologically-oriented society. One might argue that "[b]y making the naturally transformative process of birth into a cultural rite of passage, a society can ensure that its basic values will be transmitted" (2). Many feel as though the process of childbirth is being "sterilized" and its cultural and emotional content diminished.

Many "non-Indigenous" North American women feel as though they are being alienated from the birthing process and have lost control of their own bodies. As such, women are increasingly seeking alternatives to hospital deliveries (3). There has been a recent and marked resurgence of homebirths and reliance on midwives. Midwifery allows women to play a larger role in their deliveries, and returns the process of childbirth to the home: roughly half of all midwifeattended births are performed in the home (4). Until 1992, midwifery was illegal in Canada when Ontario became the first province to legalize midwifery. Since then, four other provinces including Quebec have followed suit and midwifery is becoming an increasingly accepted alternative to hospital childbirths (3). In 2000, 4\% of Ontario births were attended by midwifes and by the year 2004, the percentage is estimated to rise to $10 \%$ (4).

The experience of Inuit women in the last few decades provides an even more salient example of the institutionalization of childbirth and its separation from community life. In traditional Inuit culture, an expectant woman was followed throughout her pregnancy and assisted in childbirth by a midwife and several women helpers (5). Traditional midwives received no official training, but were taught how to deliver by older women. Hence, the skills associated with midwifery were passed on from generation to generation. The knowledge of midwives was considered indispensable and midwives were accorded much respect within the community. In fact, the ability to assist in childbirth endowed women with a sense of pride and empowerment in a predominantly patriarchal society (6). In addition to an honoured position within society, a special relationship existed between the children and the midwives who delivered them. An Inuit boy gave the midwife who delivered him his first catch, and a girl, the first item she sowed (5). For the Nuu-chahnulth people of British Columbia, the term midwife translates as "she who can do everything." Hence, depriving these women of assisting in childbirth is tantamount to removing them from their influential and honoured position in society (7).

In addition to the reliance on midwives and women helpers, several other aspects of traditional Inuit childbirth are worth mentioning. Unlike current Western practices, such as those outlined in the 2002 National Guidelines for the Childbearing Years (8), an expectant woman was to remain highly active throughout her pregnancy, performing all her daily chores until the advent of labour. It was thought that such activity would give the woman the strength needed to deliver (5). Women would give birth in rapidly constructed snow houses in either a squatting or kneeling position with the midwife behind them (6). The midwife would often enlist the help of the pregnant woman's husband and female relatives, thus involving the whole family in the process of childbirth (5).

The traditional Inuit process of childbirth, as described above, was practiced without scrutiny until the 1960s. During the 1960s, so-called Nursing Stations were set up throughout the Canadian North and deliveries were relegated to officially-trained, licensed midwives within these stations. Although traditional Inuit midwives were legally excluded from these deliveries, these Nursing Stations nevertheless permitted women to deliver within their communities, surrounded by their families. Since the 1980s, however, due mostly to a shortage of professionally trained midwives, deliveries must be performed within 
hospitals in cities far removed from the Northern communities. Today, Inuit women are "evacuated" three weeks before their due date and sent to hospitals in cities, such as Winnipeg, where obstetricians perform their deliveries. Hence, within three generations, Inuit women have experienced a transition from birth performed by a traditional midwife in the context of the home and family, to birth performed by a professional midwife in a Nursing Station within their community and presently, to birth performed by a physician in a hospital far removed from their community $(5,6)$.

Since the practice of sending women to distant hospitals began, Inuit women have repeatedly expressed their dissatisfaction with the current system. In fact, since its inception in 1984, a primary concern of the Inuit Women's Association has been the issue of childbirth $(5,9)$. The concerns about the system in place centre around five main issues: (1) the women sent to distant hospitals experience loneliness and alienation, (2) the family is removed from the process of childbirth, (3) the separation of the expectant woman from her husband and children causes undue strain on their relationship, (4) the skills and knowledge of traditional Inuit midwives are being eradicated, and (5) Inuit children are receiving out-of-territory birth certificates. Inuit women feel as though their control over childbirth has been usurped by the government and that they have now become dependent on health care services. The status previously endowed by the knowledge of childbirth on midwives and women in general has been perturbed by the forced reliance on the expertise of faraway physicians.

According to John O'Neil and Patricia A. Kaufert (6), the practice of sending Inuit women to distant hospitals is a manifestation of "internal colonialism." Although a discussion of Inuit childbirth as an extension of colonialism is beyond the scope of this paper, this idea serves to illustrate the clash of cultures at hand. The imposition of the Western culture's birthing practices on the Inuit community has left many Inuit feeling robbed of yet another aspect of their culture and heritage. The Western culture which tends to dissociate childbirth and illness, in general, from community life is in sharp contrast to the Inuit culture which views childbirth and illness as being integral and continuous aspects of community life (6).

As the current situation remains unfavourable to the majority of Inuit women, a compromise of some sort must be reached. Such a compromise was articulated at a workshop held in the Inuit community of Keewatin in 1988 and relies on a cooperation between traditional midwives and obstetricians such that high-risk deliveries would be performed by obstetricians and low-risk deliveries by traditional midwives. Although the death of a newborn was traditionally viewed as "meant to be," Inuit women overwhelmingly approve of seeking the expertise of an obstetrician for high-risk deliveries, but wish to be given the choice to have their births performed by traditional midwives in the case of low-risk deliveries. A spokeswoman for the Inuit Women's Association spoke of a system that will "look into the past to find the elements that can be adapted to contemporary conditions to ensure that the knowledge and experience of the elder midwives is retained as part of Inuit heritage (5)". Others, however, are proponents of a more confrontational approach. Women in the community of Puvirnituq have returned to performing traditional-style births and have reclaimed their dominion over the childbirth process (10). These women are doing so illegally. When Quebec legalized midwifery in 1999, Quebec law failed to recognize training programmes other than the one offered at the Université du Québec in Trois-Rivières. The women training at the Innuulitsivik Health Centre in Puvirnituq are unable to apply for a midwifery license. Negotiations are under way between the provincial Ministry of Health and the Inuit community, and offer promise that the traditional apprenticeship model of training midwives will be officially recognized (7).

It is likely that in the years to come, the trend towards the deinstitutionalization of childbirth will be amplified, though technology's value in reducing infant and maternal mortality will undoubtedly ensure that it remains an integral component of childbirth. However, "[t]he issue is not whether technology is good or bad in and of itself, but under what circumstances should it be used, when does it augment the quality of life of those who use it, when does it detract from that quality, and, perhaps, most importantly, who has the power to decide what is appropriate use (11)." A better understanding of these issues and a discussion of the needs and concerns of those involved will likely enhance the quality, safety and diversity of tomorrow's childbirth practices.

Gillian Morantz-Ornstein, B. Sc.

Louis-Patrick Haraoui, B. Sc.

McGill University

\section{REFERENCES}

1. Kitzinger S. Women as Mothers: How They See Themselves in Different Cultures. New York, NY: Vintage Books, 1980.

2. Davis-Floyd RE. Birth as an American Rite of Passage in Childbirth in America: Anthropological Perspectives. In: Michaelson KL, editor. South Hadley, MA: Bergin and Garvey Publishers, 1988.

3. Davis-Floyd RE, Sargent C. Introduction: The Anthropology of Birth Childbirth in Childbirth and Authoritative Knowledge: Cross-Cultural Perspectives. In: Davis-Floyd, RE, Sargent CF, editors. Berkeley, CA: University of California Press, 1997. 
4. Holliday T. The re-emergence of Canadian midwifery: A profession dedicated to normal birth. 2001 www.birthinternational.com

5. O'Neil JD, Gilbert P. Childbirth in the Canadian North: Epidemiological, Clinical and Cultural Perspectives. Winnipeg, MB: University of Manitoba, 1990.

6. O'Neil JD, Kaufert P. The Politics of Obstetric Care: The Inuit Experience in Births and Power: Social Change and the Politics of Reproduction. In: Handwerker W. Boulder, CO: Westview Press, 1990.

7. Carrol D, Benoit C. Aboriginal midwifery in Canada: Blendingtraditional and modern forms. CWHN Network 4:5-10; 2001

8. Nutrition for a Healthy Pregnancy- National Guidelines for the
Childbearing Years, Health Canada, 2002.

9. Inuit Women's Association. 1984-1985 Resolutions. http://www.pauktuutit.on.ca/resolutions/84-85.html

10. Daviss BA. Heeding Warnings from the Canary, the Whale, and the Inuit. A Framework for Analyzing Competing Types of Knowledge about Childbirth in Childbirth and Authoritative Knowledge: Cross-Cultural Perspectives. In: Davis-Floyd, RE, Sargent CF, editors. Berkeley, CA: University of California Press, 1997.

11. Michaelson KL. Birth Place/Birth Style in Childbirth in America: Anthropological Perspectives. In: Michaelson KL. South Hadley, MA: Bergin and Garvey Publishers, 1988.

Gillian Morantz-Ornstein is a second year medical student at McGill University. She holds a B.Sc. in psychology and criminology from Duke University, North Carolina, USA. She is a former Hart Fellow in Harare, Zimbabwe and is currently involved in public health research on street youth and human rights activism. Louis-Patrick Haraoui is a second-year medical student at McGill University, where he previously completed a B.Sc. in Microbiology and Immunology. He will be starting his MA in Medical Antropology next Fall. His thesis work will focus on the determinants that affect the health of refugee populations.

\section{SUFFER THE LITTLE CHILDREN}

Doctors and patients have come to expect a cure for most every illness and condition. Unfortunately for both groups, this is not always possible. When faced with the prospect of the imminent death of a patient, doctors may exhibit curative attitudes and perform interventions which may not be in the best interest of the patient. Referral to palliative care may become the only appropriate avenue of treatment, yet it may never be offered. Nowhere is this seen more clearly than in the treatment of a dying child. The lack of healing services provided to terminally ill children is alarming. This dearth of pediatric palliative care stems from the history of palliative care, societal attitudes about dying children, the current standard of medical education, the limited experience of pediatricians with death, and the issues of required parental consent. These factors cumulatively affect the interactions between doctors, parents and children faced with a terminal illness.

The World Health Organization has defined pediatric palliative care as "the active total care of patients whose disease is not responsive to curative treatment. Control of pain, of other symptoms and of psychological, social and spiritual problems is paramount. The goal of palliative care is achievement of the best quality of life for patients and families (1)." Contemporary society is obsessed with curative treatment. The last one hundred years have seen a dramatic increase in medical technology. Many once-fatal diseases are now mere inconveniences and science has given doctors incredible tools to eradicate illness and death. With respect to children, world mortality rates have been declining steadily. The chance of a newborn dying before its fifth birthday is seven percent, down from 25 percent in 1950 (2). This decrease is due largely to advances like pre-natal care, antibiotics, immunizations, and surgical repair of anomalies.

Before the many scientific advances, a physician's role was fundamentally different. Without the many curative measures that we have today, death was much more common and different skills were in demand. Because of their inability to cure, doctors used a palliative approach to comfort and ease the burden of death on patients and their families. Today the curing role has superceded this healing role because science has given us the opportunity to do so.

The ability to cure has changed the focus of medicine. With all the life-saving measures that exist, it is difficult for many to believe that nothing curative can be done. While the ability to prolong life may be possible, it is questionable whether or not it is advisable. In medicine, curing has been associated with life while palliative care has been linked with death. One reason why these associations exist: it seems to be easier for physicians and family to accept that a person died because heroic measures failed.

This direct association of palliative care with death makes its implementation an uncomfortable decision when children are concerned. Dying children defy the natural order (3). While elderly individuals and their families may be more open to palliative care, parents and doctors of children seem to be reluctant to implement it. Those who have lived a long life are more apt to accept its final, inevitable, conclusion. Since they hold out no hope for a permanent cure, palliative care 